\title{
Dominant Factors for Online Trust
}

\author{
Chao-Jung Hsu \\ Department of Management, Logan Campus, Griffith University, Meadowbrook, QLD, 4131, Australia
}

$\underline{\text { Chao-Jung.Hsu@student.griffith.edu.au }}$

\begin{abstract}
The uses of the World Wide Web on the Internet for commerce and information access continue to expand. The e-commerce business has proven to be a promising channel of choice for consumers as it is gradually transforming into a mainstream business activity. However, lack of trust has been identified as a major obstacle to the adoption of online shopping. Empirical study of online trust is constrained by the shortage of high-quality measures of general trust in the e-commence contexts. Based on theoretical or empirical studies in the literature of marketing or information system, nine factors have sound theoretical sense and support from the literature.

A survey method was used for data collection in this study. A total of 172 usable questionnaires were collected from respondents. This study presents a new set of instruments for use in studying online trust of an individual. The items in the instrument were analyzed using a factors analysis. The results demonstrated reliable reliability and validity in the instrument.

This study identified seven factors has a significant impact on online trust. The seven dominant factors are reputation, thirdparty assurance, customer service, propensity to trust, website quality, system assurance and brand. As consumers consider that doing business with online vendors involves risk and uncertainty, online business organizations need to overcome these barriers. Further, implication of the finding also provides e-commerce practitioners with guideline for effectively engender online customer trust.
\end{abstract}

Keywords: e-commerce, online trust

\section{INTRODUCTION}

The explosive growth of the World Wide Web on the Internet has given rise to a promising locus of commerce. Through e-commerce, businesses have the opportunity to sell products and services 24 hours a day and to reduce costs associated with personnel and retail space. Also, online businesses have more chances of attracting new consumers and having worldwide exposure. Whereas electronic commerce (ecommerce) can save time and vanquish spatial barriers [57], [63], e-commerce has been widely spread in the popular business press for providing new ways to create business value and driving strong economic progress.

According to [36], online retail sales reached US $\$ 81$ billion in the United States in 2005, and are expected to grow by an annual of $17 \%$ in 2006 to US\$95 billion. The report also reveals that the Internet will influence nearly half of total retail sales in 2010 , compared to just $27 \%$ in 2005 . A recent report from [1] indicates that $31 \%$ of Australian adults purchasing or ordering goods or services over the Internet increased significantly in 2004-05, and compared to just 5\% in 1999. This trend indicates remarkable potential and demonstrates that e-commerce has proven to be a promising channel of choice for consumers [51].

The use of e-commerce in business is gradually transforming into a mainstream business activity. Since the transactions take place without personal contact and handling products, consumers in the e-commerce marketplace are more vulnerable than in the traditional marketplace. For example, Internet users fear a credit card fraud or theft, personal information being share, not receiving the right products, and difficult to return product [4], [13]. Many potential online consumers terminate their online transactions for security or privacy reasons [1], [30]. Online retailers recognize that online consumers decide to shop online because they trust that the retailer has ability to secure their transaction and information [55]. Without complete confidence, consumers will never make a purchase with online vendors [15]. Trust mitigates the feelings of uncertainty that arise when the shop is unknown, the shop owners are unknown, the quality of product is unknown, and the performance of post-purchase service is unknown. All of these conditions are likely to arise in an e-commerce environment. Trust mainly affects consumer behavior and consequently the Internet retailer need to cultivate trustworthiness for consumers to continue the growth of the ecommerce marketplace [9].

There are a considerable number of factors related to online trust that require special understanding with respect to the ecommerce environment. These include reputation, security, privacy, customer service, and website quality [15], [32], [54]. Despite a vast amount of theoretical literature, there is little empirical research into how all dominant factors impact on online trust. This study focuses on developing an instrument to investigate the consumer's perceptions of online trust in the ecommerce environment between the consumer and the store.

The remainder of the paper is organized as follows: Section 2 defines online trust for this study and reviews relevant research. Section 3 describes the research framework. Section 4 reports the findings. Final Section concludes the finding.

\section{Literature review}

\subsection{Definition of online trust}

While there are many different definitions of trust in different disciplines, some researchers have argued that some definitions of trust are too abstract to be useful for conceptual or empirical work [5]. Reference [5] called for specifying the domain and connotative meaning of the trust construct in the context of a certain discipline.

The aim of this study focuses solely on the consumer's perceptions of online trust in the e-commerce environment 
between the consumer and the store. The focus is on developing a framework to explain online trust, and developing a robust and conceptually appealing definition of online trust that can be used in e-commerce (individual buyer) contexts.

In this study, the definition of online trust is adapted from [46] - "online trust is the willingness of a consumer to be vulnerable to the actions of an online store based on the expectation that the online store will perform a particular action important to the consumer, irrespective of their ability to monitor or control the online store". This definition is general enough to encompass trust for all types of operations and transactions. It is specifying the realm and implicative meaning of the online trust construct in the e-commerce context in several ways. First, across disciplines there is agreement that trust only exists in an uncertain and risky environment. Online trust also exists in uncertain or vulnerable situations controlled by online store. Second, online trust is expectancy or predictability. It cannot exist without some possibility of being in error. Third, online trust requires mutuality. There must be a trusting party (trustor) and a party to be trusted (trustee) in any trust relationship. Fourth, online trust is related to good (or nonnegative) outcomes.

\subsection{Factors for online trust in e-commerce}

A significant body of knowledge from several research streams shed light on how trust forms. Drawing from those theoretical streams, a number of trust antecedents have been identified in the literature. Based on these theoretical or empirical constructs, the trust antecedents of interest in this study are personality-based trust, knowledge-based trust and institution-based trust. They are discussed below.

\subsubsection{Personality-based trust}

Personality-based trust or propensity to trust is defined as the extent to which one displays a consistent tendency to be willing to depend on others across a broad spectrum of situations and persons [46], [47], [48]. This form of trust is based on a belief that others are typically well-meaning and reliable. These beliefs are a trust credit that is influenced by cultural background and personality type [46]. Such a disposition is especially important in the initial stages of a relationship [46], [47]. Later, as people interact with the trusted party, these dispositions are molded by certain childhood-derived attributes that have become more or less stable over time because people are more influenced by the nature of the interaction itself [47].

Existing research has revealed that an individual's propensity to trust is related to consumer trust in the ecommerce context. For example, research conducted by [22] and [24] based on online shopping with Amazon.com suggested that propensity to trust has a positively significant association with consumer trust. This evidence suggested that propensity to trust should be especially important for inexperienced online consumers, since, in the absence of social cues and experience with an online retailer, new consumers are forced to base their trust primarily on their socialized propensity to trust [22]. Findings from a study carried out by [60] in U.S.A., Singapore, and China indicated that propensity to trust has a positive impact on consumer trust in electronic commerce. Similarly, the research conducted by [67] also suggested that propensity to trust positively affects online trust.

\subsubsection{Knowledge-based trust}

Knowledge-based trust is based on the predictability of the other party; that is through knowing the other sufficiently well that their behavior is predictable [41]. It assumes that the parties have first-hand or second-hand knowledge of each other. First-hand knowledge requires a familiarity with the online vendor. If there is no interaction history with the particular party, consumers do not trust most Internet stores enough to engage in "relationship exchanges" that involve money and personal information [32]. While the second-hand knowledge, like store reputation, brand name, and store size may influence trust, one missing factor is the implicit comfort of face-to-face communication present in physical interactions [6]. The knowledge-based trust such as familiarity, reputation, brand, size, website quality, and customer service will be discussed below.

\subsubsection{Familiarity}

Knowledge-based trust antecedents such as familiarity with the online vendor suggest that trust develops over time. That is, it accumulates over time as the relationship develops with the accumulation of trust. Thus, the development of trust between parties requires time and an interaction history [47]. Familiarity is experience with the what, who, how, and when of what is happening. While trust reduces social complexity relating to future activities of the other party, familiarity reduces social uncertainty through an increased understanding of current actions of the store [45].

In e-commerce, consumer familiarity, for example, corresponds to how well a consumer comprehends the website procedures, including when and how to enter credit card information [22]. Accordingly, familiarity with a trustworthy online vendor should increase consumer trust. This occurs because more familiarity implies an increasing amount of accumulated knowledge derived from experiencing previous successful interactions through the website [22]. People tend to trust the familiar, and familiarity obtained through frequent exposure has the potential to engender trust.

\subsubsection{Reputation}

Reputation is conceptualized as the consumer's perception of a store's reputation, where reputation is defined as the extent to which consumers believe a store is honest and concerned about its consumers [17]. Where consumers do not have personal experience with a vendor, word-of-mouth reputation can be a key to attracting consumers. Hearing from others of their positive experience with a vendor can help ease users' perceptions of risk and insecurity when interacting with the online vendor. According to [47], online vendors with a good reputation are seen as trustworthy and those with a bad reputation are seen as untrustworthy. Furthermore, the reputation of an online vendor is likely to influence a buyer's trust towards that vendor [20], [34], [54]. Hence, a good reputation suggests certainty and less risk in conducting 
business, and so helps foster consumer trust. For example, the reputation of Amazon.com has helped to boost its sales [2].

Some empirical studies related to the reputation of an online vendor associated with trust have been identified in the literature. For example, research carried out by [34] based on online shopping with books or travel, suggested that the reputation of online vendor has a positive impact on online trust. Similarly, the findings demonstrated that the perceived reputation has a significant affect on consumer trust in the ecommerce context [60], [65]. Whereas, the larger the perceived reputation is, the greater the trust in the company.

\subsubsection{Brand}

According to [39, p 442], brand can refer to "a name, term, sign, symbol, or design, or combination of them which is intended to identify the goods and service of one seller or group of sellers and to differentiate them form those of competitors". Researchers have identified brand as a surrogate for trust [16], [27], [28]. Reference [35] proposed that Internet brand development is more relevant to service branding than physical goods, primarily due to intangibility, technology, and other benefits, all of which contribute to a degree of trust dependency. Reference [3] pointed out that branding is not only relevant for tangible goods but also a critical success factor for service providers. Brand is used "as the function for building trust-based relationships with customers" [3, p2]. Strong brands increase consumers' trust of the products that they can not physically inspect while helping them to better understand and visualize what they are buying [70].

Reference [21] indicated that brands were initially thought to be less significant online, particularly in commodity markets where easy comparison would focus attention on price. However, brands offer benefits to the consumers. Consumers in online marketplaces have to rely on electronic information without having the ability to physically inspect the product. Further, uncertainty about product quality can also be a problem for consumers in the online environment. Branding, in the same way, simplifies decision-making by standing for the missing knowledge. In the online environment, the brand stands as a symbol of quality and assurance [70]. Reference [15] stated that brands are important for e-commerce for several reasons. Brands help shoppers make their choice when they have a limited range of clues about the quality and functionality of products. Without brand awareness, consumers may not even know an online store existed. Although an online store may offer high-quality products at lower prices, the consumer may be skeptical over quality, compared with higher priced but better known online brands. While having a wellknown brand reduces the risks for consumers in doing business with a leading online vendor [7], familiar brands with established records of performance help in building trust [15]. Due to their well-known brands, Internet market leaders are more highly trusted by consumers [62]. Thus, brand should be an important factor for new consumers to initialize online trust.

\subsubsection{Size}

Reference [17] stated that the size of vendor is comprised of its overall size and market share position in traditional retailing environment. Since a vendor with a large market-share should serve a more diverse and heterogeneous set of consumers [26], research suggests that the large vendor consistently delivers on its promise to its consumers and so many consumers tend to trust it. If this was not the case, it would not be able to maintain its position in the industry [17]. Large organizational size also indicates that the vendor is likely to possess expertise and the necessary support systems that engender trust and loyalty [12]. In an e-commerce environment, consumers consider that the larger the size of a vendor, the better they are able to guarantee their products or services so that the risk of product failure or the loss of transaction is reduced. Therefore, the large-sized vendor has the ability to compensate buyers if such a loss occurs [34].

\subsubsection{Website quality}

Reference [56] suggested website quality should be judged by the quality of content, structure and navigation, and functionality. Content is the information provided on the site. Good content should be engaging, relevant, and appropriate for the consumer. It may be informative, useful, or funny but it always leaves consumers wanting more. Structure and navigation refers to the organization of information on the site and the method in which users move through sections. Sites with good structure and navigation are consistent and effective. Good navigation gets users where they want to go quickly and offers easy access to the breadth and depth of the site's content. Functionality is the use of technology on the site. Good functionality means the site loads quickly, has live links, and any new technology used is functional and relevant for the intended audience. The site should work cross-platform and be browser independent. Good functionality is technology that is transparent to the user.

In the traditional environment, the most salient source of trust in a retail setting is the salesperson, where consumer trust is dependent on the salesperson's expertise, likeability, and similarity to the consumer [17]. However, with online shopping, this physical salesperson is replaced by help buttons and search features, thus removing the traditional basis of consumer trust in the shopping experience [43]. In the online environment, a well-designed website of an online vendor should provide consumers with sufficient information for making purchase decisions, user-friendly navigation, smooth vendor interaction, and an easy ordering procedure. It should influence consumers to trust an online vendor as does a salesperson in traditional retailing environment.

An empirical result from [14] suggested that perceived website quality has a positive impact on trust from Internet users in New Zealand. Similarly, the findings demonstrated that website quality strongly correlates with trusting beliefs in online banking [70]. In general, a good quality of website should enhance the formation of consumer trust in online environments.

\subsubsection{Customer service}

Reference [64, p246] defined customer service as "an organizational perspective and process that focuses on meeting customer expectations by doing the right things right the first 
time". The process by which an organization delivers its services or products allows the consumer to access them in the most efficient and cost effective way and so meet the consumer's expectations.

Some researchers stated that firms can maintain consumer retention by responding to service failures in a fair manner [33], [50]. These findings suggest that purchase intentions will remain stable, and possibly increase, when service recovery is effective. These findings imply that effective customer service also decreases consumer risk and inspires trust again. On the other hand, a poor customer service effort may substantially reduce their future intentions to purchase from the failing firm, because the firm does not keep its promise and that dramatically reduce the trustworthiness of the firm. Therefore, this study considers that an effective customer service will affect trust between consumers and online vendors.

\subsubsection{Institution-based trust}

The concept of institution-based trust proposed by [47] represents the beliefs held by consumers about impersonal structures and favorable conditions, in which they feel safe, assured, and comfortable with the prospect of depending on the business. The following subsections propose some trustbuilding strategies based on structural-assurance mechanism. These include perceived security, perceived privacy and thirdparty assurance.

\subsubsection{Perceived security}

Security has been widely recognized as one of the major obstacles to adoption of e-commerce [19]. Security has been defined as the protection against the threat that creates "circumstance, condition, or event with the potential to cause economic hardship to data or network resources in the form of destruction, disclosure, modification of data, denial of service, and/or fraud, waste, and abuse" [37, p177]. Using this definition, in the context of electronic commerce, threats can be made either through network and data transaction attacks or through unauthorized access to the account. The means by which unauthorized access to account occurs is via false or defective authentication such as the theft of credit card information, or stealing of personal information. Perceived security then is the consumers' perception of the degree of protection against these threats. Security controls that provide technological and organizational support to e-commerce, ensure timely and accurate completion of transactions, prevent fraud and third-party manipulation, assure smooth transactions, and safeguard transaction authentication to insure against damage.

Some empirical findings indicated that perceived security is positively associated with trust in e-commerce contexts [9], [66], [70]. Similarly, in [69], transaction security was the most important antecedent of online purchase intention with a mediator of trust or website satisfaction. According to the prior research, as perception of security risk decreases, trust on an online store is expected to increase.

\subsubsection{Perceived privacy}

Perceived privacy is defined as "the subjective probability with which consumers believe that the collection and subsequent access, use, and disclosure of their private and personal information is consistent with their expectations" $[8$, p13]. Privacy involves the protection of personal information not sharing personal information collected about consumers with other sites, protecting anonymity, and providing informed consent [20].

Public opinion surveys continue to find that a majority of consumers express concern about losing control over the ways in which organizations handle their personal information [30]. The ultimate aim of perceived privacy is to enhance autonomy and/or minimize vulnerability. Control over information is a key dimension of privacy and has been stressed by researchers in diverse disciplines. Consumers in an online environment, contrary to traditional retail environment, perceived little control over information privacy. This has a striking influence on their willingness to engage in exchange relationships with online vendors. It is the willingness of consumers to share information over the Internet that allows purchases to be concluded. However, it is clear that consumer concern with information privacy is having an impact on the consumer Internet market. For the e-commerce to reach its full potential, privacy concerns must still be addressed further.

There are some empirical studies within e-commerce contexts that provide contrary findings in perceived privacy to inspire trust [8], [42], [66], [70]. Their findings indicated that perceived privacy is positively associated with trust in ecommerce contexts [42], [70]. Whether online vendors are able to protect personal information and prevent credit card misuse is a major concern for Internet users when shopping online.

\subsubsection{Third-party assurance}

In the electronic commerce context, consumers have no control over the online vendors, no guarantee of the quality of the online content, and no power to influence the sites' behavior. Therefore, certification third parties or intermediary mechanisms such as TRUSTe, BBBOnLin, CPA WebTrust, Verisign, insurance, etc. can balance the power and create the needed trust between the online vendor and its consumers.

The independent nature of third-party certification has been developed by the e-commerce industry in order to help consumers feel more trusting when conducting business with websites. Insurance, the other intermediary mechanism, is aimed at protecting consumers by reducing risks and inspiring trust [59]. Insurance refers to social arrangement in which there is a promise to compensate individuals for future harm if it occurs. Consumers are mostly concerned with the monetary aspect of e-commerce transactions, as opposed to the means through which the transactions happen. Here it is proposed that by removing the liability of an unauthorized transaction, the consumers will increase trusting beliefs about the service provider. The shift of liability and provision of a guarantee transfer the burden of security threats from the consumer to the online service provider. It is therefore justified to argue that consumers would perceive a transaction would occur in 
accordance with their confident expectations, if the risk of disputed transactions were no longer their own responsibility [70]. In e-commerce contexts, insurance is often offered in terms of financial compensation such as fully covering the cost of a credit card purchase that goes wrong or via some other arrangement such as seeking to cover data destroyed by mistake [20]. Whereas the insurance company ensures that the provided guarantee is comprehensive, most consumers were enthusiastic about using insurance as a surrogate for affecting trust on the e-commerce environment [59]. Therefore, providing insurance on e-commerce contexts should influence consumer trust.

There are some empirical studies on e-commerce contexts to provide contrary findings on the ability of Web seals to inspire trust [23], [38], [49], [70]. Their findings revealed that displaying a Web seal on website has a positive impact on online trust [23], [38].

\section{Research framework}

A more detailed discussion drawn from several research streams was provided above. It classified nine factors from empirical point of view to identify which factors should be included to measure online trust for this study and provided a framework of online trust (Figure 1) to measure the trust online in the e-commerce environment.

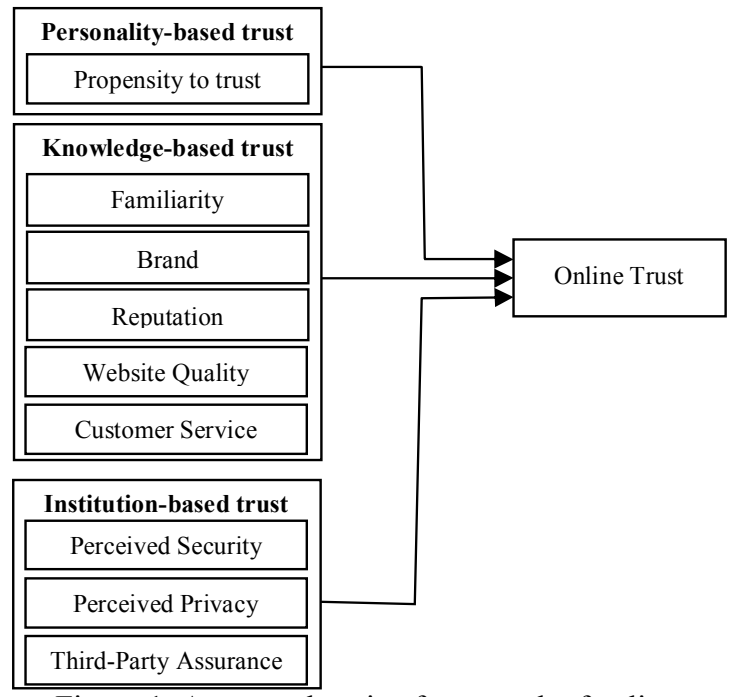

Figure 1: A comprehensive framework of online trust

With personal-based trust, new consumers or inexperienced consumers in the absence of social cues and experience with an online store and their tendency to initiate a relationship with an online store is primarily based on their propensity to trust [22].

With knowledge-based trust, trust develops over time. Thus, the development of trust between parties requires time and experience. Experience such as familiarity, website quality and customer service reduces social uncertainty through increased understanding of function of the store's activities. Further, the better the reputation and brand name of online store has, the more trustworthy the online store will be. On the other hand, the perceived size of an online vendor does not influence consumers trust in the same way as the perceived size of a traditional vendor does. Further, the size of an online vendor is not easily or correctly judged through its website as in the case with a physical store is. Hence, consumers tend to recognize reputation and brand, and do not place much reliance on the size of online vendor. Perceived size is consequently excluded from this study.

The discussion on institutional-based trust identified third trust-building strategies (perceived security, perceived privacy and third-party assurance). In the definition of online trust "the online store will perform a particular action important to the consumer", many successful methods adopted by e-commerce companies to overcome trust barriers are in institution-based trust antecedents reflecting that an online store will perform a particular action to secure consumers' feelings about their situation are guaranteed and safe.

Based on the review of the literature, this study classified items for each factors from existing studies. The factors were: online trust [22], [23], [31], [34], [40], [48], reputation [34], [40], [60], perceived security [10], [40], [61], [63], perceived privacy [10], [8], [64], [63], propensity to trust [10], [22], [48], [60], [67], third-party assurance [10], [23], familiarity [22], [23], [67], website quality [11], [14],[44], [48], brand [18], [68], and customer service [58].

\section{Method}

\subsection{Participants}

This study focuses on consumer trust in the e-commerce commerce contexts and the target population should be Internet users. University students were chosen as the research population for this study. The selection of subjects was deemed to be appropriate for the following reasons:

- The majority of Internet users are generally younger and more highly educated than conventional consumers, which make university student samples closer to the online consumer population [48].

- The majority of adult Internet users have a university education and this population represents the fastest growing group of Internet users [53].

- University students are a very good target group for research study in the field of e-commerce, since they have free access to the Internet and have the opportunity to use this medium for communication and commercial transactions [65].

\subsection{Data collection methods}

All data were collected through a survey constructed to measure the following variables: online trust, propensity to trust, familiarity, brand, reputation, website quality and customer service, perceived security, perceived privacy, thirdparty assurance and key demographic characteristics.

All the constructs of the framework were measured using multiple items based on scales obtained from the literature as shown in the previous chapter. All items were assessed via 7 point interval scale ranging from strongly disagree (1) to strongly agree (7). The survey was administered by the researcher during class time in the first or second week of the 
second semester 2006. Students were made aware that participation in the study was voluntary. A 172 complete inquires were collected from 182 students. The gender distribution of the respondents was 54.7 percent female and 45.3 percent male. The majority of the respondents were under 30 years old; 41.9 percent under 20 and 48.8 percent between 20 and 29 years old.

\subsection{Results}

Because of the exploratory nature of this study, a principal component factor analysis was used to confirm initial factors for online trust. Reference [29] stated the more acceptable case-to-variable ratio is ten-to-one ratio and if the study has a low case-to-variable ratio then PROMAX rotation methods should be applied. This study uses 172 cases to measure 34 variables and thus the case-to-variable ratio is five-to-one. Since the case-to-variable ratio is low, the PROMAX-rotation with Kaiser Normalization as recommended by [29] was used. Any missing values were replaced by the mean as noted above.

Table 1: Final PROMAX-Rotated Factor Loadings

\begin{tabular}{|c|c|c|c|c|c|c|c|}
\hline Item & Factor 1 & Factor 2 & Factor 3 & Factor 4 & Factor 5 & Factor 6 & Factor 7 \\
\hline Rep2 & .970 & .083 & -.202 & -.052 & -.103 & .059 & .114 \\
\hline Rep3 & .913 & .076 & -.051 & -.002 & .016 & .000 & .013 \\
\hline Rep1 & .880 & -.050 & -.171 & .042 & .023 & .106 & .087 \\
\hline Rep6 & .866 & -.118 & .175 & -.020 & -.021 & -.129 & -.065 \\
\hline Rep4 & .812 & -.084 & -.006 & .039 & .042 & -.010 & .061 \\
\hline Rep5 & .735 & -.059 & .195 & .034 & .176 & -.114 & -.209 \\
\hline WebQ1 & -.028 & .960 & -.164 & -.004 & -.044 & .006 & -.017 \\
\hline WebQ2 & -.043 & .920 & -.026 & .029 & .051 & -.068 & -.034 \\
\hline WebQ3 & -.020 & .880 & .059 & -.012 & -.014 & -.053 & .069 \\
\hline WebQ4 & -.015 & .787 & .111 & -.008 & .060 & .003 & -.004 \\
\hline SA3 & -.242 & -.040 & .949 & -.032 & .101 & -.045 & .161 \\
\hline SA5 & .090 & -.092 & .710 & -.002 & .100 & .037 & -.011 \\
\hline SA6 & .045 & .015 & .690 & .047 & -.043 & .047 & .187 \\
\hline SA4 & .071 & -.058 & .681 & .030 & .082 & .100 & -.060 \\
\hline SA1 & .253 & .183 & .547 & -.103 & -.051 & -.019 & -.092 \\
\hline $\mathrm{SA} 2$ & .238 & .164 & .524 & -.040 & -.231 & .046 & .068 \\
\hline Disp3 & -.008 & -.111 & -.045 & .944 & .020 & -.154 & .052 \\
\hline Disp2 & .030 & .025 & .090 & .870 & .043 & .029 & -.095 \\
\hline Disp4 & -.051 & .054 & -.160 & .825 & .032 & .025 & .056 \\
\hline Disp1 & .073 & .088 & .106 & .717 & -.132 & .135 & -.007 \\
\hline Brand3 & -.051 & -.033 & .027 & .027 & .908 & .071 & .077 \\
\hline Brand2 & .085 & .004 & .029 & -.042 & .896 & -.048 & .011 \\
\hline Brand1 & .001 & .334 & .120 & .041 & .609 & .044 & -.111 \\
\hline Third1 & -.044 & -.113 & -.080 & -.050 & .069 & .964 & .096 \\
\hline Third2 & -.031 & -.026 & .056 & -.001 & .094 & .889 & -.135 \\
\hline Third3 & .063 & .072 & .172 & .037 & -.202 & .642 & -.050 \\
\hline CS2 & .040 & .093 & -.087 & -.016 & .093 & .059 & .786 \\
\hline $\mathrm{CS} 3$ & -.025 & -.118 & .359 & .032 & -.097 & -.126 & .766 \\
\hline CS1 & .179 & .111 & .076 & -.002 & .212 & .033 & .531 \\
\hline Eigenvalue & 11.467 & 2.872 & 2.235 & 1.550 & 1.367 & 1.129 & 1.039 \\
\hline $\begin{array}{l}\text { Cumulative } \% \\
\text { of variance }\end{array}$ & 38.225 & 47.799 & 55.250 & 60.417 & 64.972 & 68.735 & 72.198 \\
\hline
\end{tabular}

Extraction Method: Principal Component Analysis. Rotation Method: PROMAX with Kaiser Normalization. a - Rotation converged in 7 iterations.

The initial analysis extracted eight factors that were evident on the scree plot and had Eigenvalues greater than 1. Several of the original factors were combined. After several iterations, the analysis retained 29 items that were loading on seven factors. The items in these factors remained unchanged and accounted for $72.198 \%$ of the total explained variance (see Table 1). All items within a given scale loaded strongly on one factor and weakly on all the other factors (items load on their own factor with coefficient greater than 0.5 , and on all other items with coefficient less than 0.4 ), thereby satisfying the requirements of validity and were deemed appropriate for further analyses.

In order to assess reliability, the Cronbach alpha [29], [52] was calculated for each of the seven identified factors. The reliability of each factor was estimated by computing its Cronbach Alpha as seen in Table 2. All factors met the reliability critical that Cronbach alpha is greater than 0.7 , as the lowest alpha was 0.796 . Therefore, these factors are considered reliable.

Table 2: Cronbach's Alpha
\begin{tabular}{|l|r|r|}
\hline \multicolumn{1}{|c|}{ Factors } & \multicolumn{1}{|c|}{ Items } & Cronbach's Alpha \\
\hline Reputation & 6 & 0.920 \\
\hline System Assurance & 6 & 0.885 \\
\hline Propensity to Trust & 4 & 0.890 \\
\hline Third-party Assurance & 3 & 0.796 \\
\hline Website Quality & 4 & 0.894 \\
\hline Brand & 3 & 0.868 \\
\hline Customer Service & 3 & 0.801 \\
\hline
\end{tabular}

Regression analysis was used to examine the relationship between the dominant factors and online trust. The regression model was significant $\left(\mathrm{R}^{2}=.715\right)$ at $\mathrm{p}<0.001$. As can be seen in Figure 2, propensity to trust, brand, reputation, website quality, customer service, system assurance, and third-party assurance were included as significantly contributing variables.

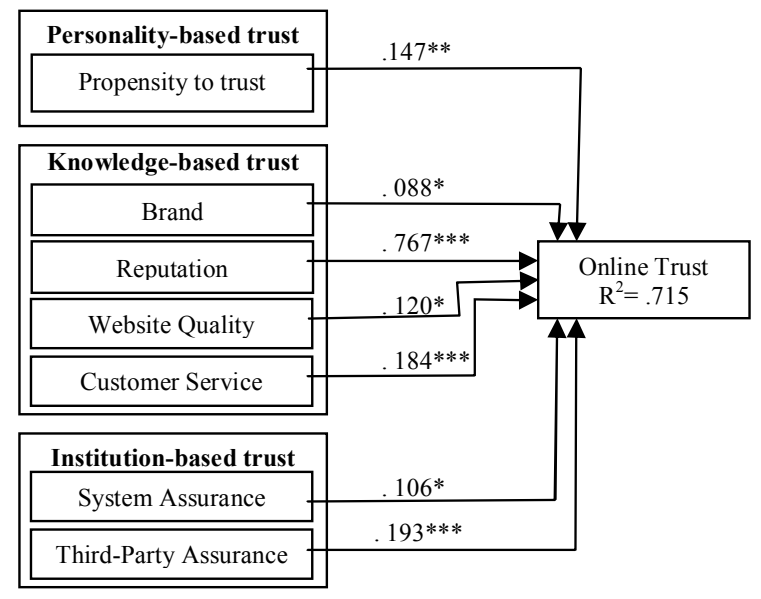

Significance level: ${ }^{* * *} \mathrm{p}<0.001,{ }^{*} \mathrm{p}<0.01,{ }^{*} \mathrm{p}<0.05$, ns $=$ non-significant

Figure 2: Regression results for instruments of online trust

\section{Conclusion}

Focusing on online trust has been a priority and one of the primary concerns in e-commerce [32]. As a relatively young research field, research on trust in e-commerce is still in the stage of borrowing different constructs from other theories and developing theoretical frameworks [25]. Reference [25] also noted that most researchers neglect some important factors that are relevant for trust-related behaviors. 
The findings from this study reveal that to better understand consumers' assessment of online trust; it is beneficial to investigate the key factors perceived by Internet users. Inasmuch as trust develops over time and is not a static but a dynamic phenomenon, this study sought to better to understand consumer's behavior from the purchase process perspective and then to identify those factors that engendered online trust. This study revealed that online vendors should focus on such online trust factors as propensity to trust, reputation, brand, system assurance, website quality, third-party assurance, and customer service.

\section{References}

[1] Australian Bureau of Statistics, "Household Use of Information Technology, Australia, 2004-05", http://www.abs.gov.au/AUSSTATS/abs@.nsf/Lookup/8146.0M ain+Features12004-05? OpenDocument, 2006

[2] S.J. Barnes and R.T. Vidgen, "An integrative approach to the assessment of e-commerce quality", Journal of Electronic Commerce Research, 3(3), pp. 114-127, 2002

[3] L.L. Berry, "Cultivating service brand equity", Academy of Marketing Science, 28(1), pp. 128-137, 2000

[4] A. Bhathagar, S. Misra and H.R. Rao, "On risk, convenience, and Internet shopping behavior", Communication of the ACM, 43(11), pp. 98-105, 2000

[5] G.A. Bigley and J.L. Pearce, "Straining for shared meaning in organizational science: Problems of trust and distrust", The Academy of Management Review, 23(3), pp. 405-421, 1998

[6] R. Bunduchi, "Business relationships in internet-based electronic markets: the role of goodwill trust and transaction costs", Information Systems Journal, 15(4), pp. 321-341, 2005

[7] Y. Cao and T.S. Gruca, "The influence of pre- and postpurchase service on prices in the online book market", Journal of Interactive Marketing, 18(4), pp. 51-62, 2004

[8] R.K. Chellappa, "Consumers' Trust in Electronic Commerce Transactions: The Role of perceived Privacy and Perceived Security", Retrieved 28 August 2006 from http://asura.usc.edu/ ram/rcf-papers/sec-priv.pdf, unpublished

[9] R.K. Chellappa and P.A. Pavlou, "Perceived information security, financial liability and consumer trust in electronic commerce transactions", Logistics Information Management, 15(5/6), pp. 358-368, 2002

[10] M.K. Cheung and K.O. Lee, "Trust in Internet Shopping: Instrument Development and Validation through Classical and Modern Approaches", Journal of Global Information Management, 9(3), pp. 23-35, 2001

[11] J. Cho, "The mechanism of trust and distrust formation and their relational outcomes", Journal of Retailing, 82(1), pp. 2535,2006

[12] S. Chow and R. Holden, "Toward and understanding of loyalty: The moderating role of trust", Journal of Managerial Issues, 9(3), pp. 275-298, 1997

[13] E. Constantinides, "Influencing the online consumer's behavior: the Web experience", Internet Research, 14(2), pp. 111-126, 2004

[14] B.J. Corbitt, T. Thanasankit and H. Yi, "Trust and e-commerce: a study of consumer perceptions", Electronic Commerce Research and Applications, 2, pp. 203-215, 2003

[15] S. Dayal, H. Landesberg and M. Zeisser, "How to build trust online", Marketing Management, 8, pp. 64-69, 1999
[16] E. Delgado-Ballester and J.L. Munuera-Aleman, "Brand trust in the context of consumer loyalty", European Journal of Marketing, 35(11/12), pp. 1238-1259, 2001

[17] P.M. Doney and J.P. Cannon, "An examination of the nature of trust in buyer-seller relationships", Journal of Marketing, 61(2), pp. 35-51, 1997

[18] N. Donthu, "Does your web site measure up?", Marketing Management, 10(4), pp. 29-32, 2001

[19] S.M. Furnell and T. Karweni, "Security implications of electronic commerce: a survey of consumers and businesses", Internet Research, 9(5), pp. 372, 1999

[20] B. Friedman, P.H. Kalm Jr. and D.C. Howe, "Trust online", Communication of the ACM, 43(12), pp. 34-40, 2000

[21] J.M. Gallaugher, "E-commerce and the undulating distribution channel", Communication of the ACM, 45(7), pp. 89-95, 2002

[22] D. Gefen," E-commerce: The role of familiarity and trust", Omega, 28, pp. 725-737, 2000

[23] D. Gefen, E. Karahanna and D.W. Straub, 'Trust and TAM in online shopping: An integrated model', MIS Quarterly, 27, pp. 51-90, 2003

[24] D. Gefen, E. Karahanna and D.W. Straub, "Inexperience and Experience with Online Stores: The Importance of Tam and Trust", IEEE Transactions on Engineering Management, 50, pp. 307-321, 2003

[25] S. Grabner-Krauter and E.A. Kaluscha, "Empirical research in on-line trust: a review and critical assessment", International Journal of Human-Computer Studies, 58, pp. 783-812, 2003

[26] A. Griffin and J.R. Hauser, "The voice of the customer", Marketing Science, 12(1), pp. 1-27, 1993

[27] H.Y. Ha, "Factors influencing perceptions of brand trust online", The Journal of Product and Brand Management, 13(4/5), pp. 329-342, 2004

[28] H.Y. Ha and H. Perks, "Effects of consumer perceptions of brand experience on the web: Brand familiarity, satisfaction and brand trust", Journal of Consumer Behavior, 4(6), pp. 438-452, 2005

[29] J.F. Hair, R.E. Anderson, R.L. Tatham and W.C. Black, "Multivariate Data Analysis 5th Ed.", Prentice Hall: Upper Saddle River, NJ, 1998

[30] Harris Interactive, "New Data Show Internet, Website and Email Usage by Physicians All Increasing", http://www.harrisinteractive.com/news/newsletters/healthnews/ HI HealthCareNews2001Vol1 iss8.pdf, 2001

[31] H. Heijden, T. Verhagen and M. Creemers, "Understanding online purchase intentions: Contributions from technology and trust perspectives", European Journal of Information Systems, 12(1), pp. 41-48, 2003

[32] D.L. Hoffman, T.P. Novak and M. Peralta, "Building consumer trust online", Communications of the ACM, 42, pp. 80-85, 1999

[33] J.W. Huppertz, S.J. Anderson and R.H. Evans, "An application of equity theory to buyer-seller exchange situations", Journal of Marketing Research, 15, pp. 250-260, 1978

[34] S.L. Jarvenpaa, N. Tractinsky and M. Vitale, "Consumer trust in an Internet store", Information Technology and Management, 1(1-2), pp. 45-71, 2000

[35] C. Jevons and M. Gabbott, "Trust, Brand Equity and Brand Reality in Internet Business Relationships: An Interdisciplinary Approach", Journal of Marketing Management, 16, pp. 619634, 2000

[36] Jupiter Research, "JUPITERRESEARCH FORECASTS ONLINE RETAIL SPENDING WILL REACH \$144 BILLION IN 2010, A CAGR OF $12 \%$ FROM 2005”, 
http://www.jupitermedia.com/corporate/releases/06.02.06newjupresearch.html, 2006

[37] R. Kalakota and A.B. Whinston, "Frontiers of Electronic Commerce", Addison-Wesley, United States, 1996

[38] S.E. Kaplan and R.J. Nieschwietz, "A Web assurance services model of trust fro B2C e-commerce", International Journal of Accounting Information Systems, 4, pp. 95-114, 2003

[39] P. Kotler, "Marketing management: analysis, planning, implementation, and control 7th ed.", Englewood Cliffs, N.J.: Prentice-Hall, 1991

[40] M. Kourfaris and W. Hampton-Sosa, "The development of initial trust in an online company by new customers", Information and Management, 42, pp. 377-397, 2004

[41] M.C. Lander, R.L. Purvis, G.E. McCray and W. Leigh, "Trustbuilding mechanisms utilized in outsourced IS development projects: a case study", Information and Management, 41, pp. 509-528, 2004

[42] C. Liu, J.T. Marchewka, J. Lu and C.S. Yu, "Beyond concern: a privacy-trust-behavioral intention model of electronic commerce", Information and Management, 42, pp. 127-142, 2004

[43] G.L. Lohse and P. Spiller, "Electronic shopping", Communication of the ACM, 41(7), pp. 81-86, 1998

[44] M. Long and C. McMellon, "Exploring the determinants of retail service quality on the Internet", The Journal of Services Marketing, 18(1), pp. 78-90, 2004

[45] N. Luhmann, "Trust; and, Power: two works", Ann Arbor: Michigan, 1979

[46] R. Mayer, J. Davis and D. Schoorman, "An integration model of organizational trust", The Academy of Management Review, 21, pp. $709-734,1995$

[47] D.H. McKnight, L. Cummings and N. Chervany, "Initial trust formation in new organizational relationships", The Academy of Management Review, 23, pp. 473-490, 1998

[48] D.H. McKnight, V. Choudhury, and C.J. Kacmar, "Developing and Validating Trust Measures for e-commerce: An integrative typology", Information Systems Research, 13, pp. 334-359, 2002

[49] D.H. McKnight, C.J. Kacmar and V. Choudhury, "Shifting Factors and the Ineffectiveness of Third Party Assurance Seals: A Two-stage Model of Initial Trust in a Web Business", Electronic Markets, 14, pp. 252-266, 2004

[50] R.L. Oliver and J.E. Swan, "Consumer Perceptions of Interpersonal Equity and Satisfaction in Transactions: A Field Survey Approach", Journal of Marketing, 53, pp. 21-35, 1989

[51] P.A. Pavlou and D. Gefen, "Building effective online marketplaces with institution-based trust", Information Systems Research, 15(1), pp. 37-59, 2004

[52] J.P. Peter, "Reliability: A Review of Psychometric Basics and Recent Marketing Practices", Journal of Marketing Research, 16(1), pp. 6-17, 1979

[53] R.S. Sexton, R.A. Johnson and M.A. Hignite, Predicting Internet/ e-commerce use, Internet Research, 12(5), pp. 402410, 2002

[54] K. Siau and Z. Shen, "Building customer trust in mobile commerce", Communication of the ACM, 46(4), pp. 91-95, 2003

[55] M. Singh, "E-services and their role in B2C e-commerce", Managing Service Quality, 12(6), pp. 434-446, 2002

[56] R. Sinha, M. Hearst, M. Ivory and M. Draisin, Content or Graphics? An Empirical Analysis of Criteria for AwardWinning Websites, (Retrieved 4/27/2006, from http://webtango.berkeley.edu/papers/hfw01/hfw01final/rashmi hfw01-revision2.pdf), unpublished

[57] B. Suh and I. Han, "Effect of Trust on Customer Acceptance of Internet Banking", Electronic Commerce Research and Applications, 1, pp. 247-263, 2002

[58] N. Tamimi, R. Scbastianelli and M. Rajan, "What do online customers value?”, Quality Progress, 38(7), pp. 35-39, 2005

[59] F. Tang, M.G. Thom, L.T. Wang, J.C. Tan, W.Y. Chow, and X. Tang, "Using Insurance to Create Trust on the Internet", Communication of the ACM, 46, pp. 337-344, 2003

[60] S.H. Teo and J. Liu, "Consumer trust in e-commerce in the United States, Singapore and China", The International Journal of Management Science, Omega 35, pp. 22-38, 2007

[61] G. Torkzadeh and G. Dhillon, "Measuring factors that influence the success of Internet commerce", Information systems Research, 13, pp. 187-204, 2002

[62] G.L. Urban, F. Sultan and W.J. Qualls, "Placing Trust at the center of your Internet Strategy", MIT Sloan Management Review, 42(1), pp. 39-28, 2000

[63] L.R. Vijayasarathy, "Predicting consumer intentions to use online shopping: the case for an augmented technology acceptance model", Information and Management, 41, pp. 747-762, 2004

[64] G.D. Wagenheim and J.H. Reurink, "Customer Service in Public Administration", Public Administration Review, 51(3), pp. 263-270, 1991

[65] R. Walczuch and H. Lundgren, "Psychological antecedents of institution-based consumer trust in e-retailing", Information and Management, 42, pp. 159-177, 2004

[66] S. Wang, S.E. Beatty and W. Foxx, "Signaling the trustworthiness of small online retailers", Journal of Interactive Marketing, 18(1), pp. 53-69, 2004

[67] S. Wingreen and S. Baglione, "Untangling the Antecedents and Covariates of E-Commerce Trust: Institutional Trust vs. Knowledge-Based Trust”, Electronic Markets, 15, pp. 246-260, 2005

[68] B. Yoo, N. Donthu and S. Lee, "An examination of selected marketing mix elements and brand equity", Academy of Marketing Science, 28(2), pp. 195-211, 2000

[69] Y.J. Yoon, "The antecedents and consequences of trust in online-purchase decisions", Journal of Interactive Marketing, 16(2), pp. 47-63, 2002

[70] S.Y. Yousafzai, J.G. Pallister and G.R. Foxall, ”Strategies for Building and Communicating Trust in Electronic Banking: A Field Experiment", Psychology \& Marketing, 22(2), pp. 181201, 2005 